\title{
Cesariana Pós-Morte
}

\author{
Postmortem Cesarean Section
}

Amélia Cirone Esposito Papa, Rosiane Mattar, Luiz Camano

\begin{abstract}
RESUMO
Objetivo: analisar aspectos médico-legais a fim de contribuir para o estudo e normatização desta tocurgia em nosso meio.

Métodos: nosso estudo é baseado em 11 cesarianas realizadas em situações de iminência de morte materna e cesariana pós-morte que ocorreram na UNIFESP - EPM no periodo de 1988 a 1998.

Resultados: houve 7 nativivos, dos quais 5 com idade gestacional superior a 26 semanas. A maior parte dos óbitos ocorreu até 48 horas após a internação. A faixa de idade predominante foi a $3^{a}$ década.

Conclusões: a cesariana pós-morte é operação relatada desde a antigüidade e visa salvar a vida do concepto, sendo, porém, raramente indicada. As circunstâncias inesperadas em que se impõe a cesariana pós-morte exigem prévio conhecimento das condições técnicas de sua realização, assim como de principios éticos e legais.
\end{abstract}

PALAVRAS-CHAVE: Cesariana pós-morte. Cesariana. Mortalidade materna.

\section{Introdução}

A cesariana praticada imediatamente após a morte materna (CPM) constitui o único recurso efetivo para se conseguir feto vivo. A intenção de salvar a criança mediante a secção do ventre materno foi realizada pela primeira vez em épocas remotas e se aplica até hoje. Seu relato vem desde a Mitologia Grega, com o nascimento de Esculápio, deus da Medicina, filho de Corone e Baco, extraído de Sêmele.

No histórico desta cirurgia destaca Rezende ${ }^{1}$ personagens que dela advieram: Georgius de Leontim, em 508 a.C., célebre orador da Sicília, que foi o primeiro sobrevivente; Cipião, o Africano, em 207 a.C.; Bispo de Constança em 959 d.C e o Rei Eduardo VI, em 1937.

$\mathrm{Na}$ literatura nacional, citam-se vários autores que estudaram o tema²: Fermann, em 1952 apresentou 4 casos; Nahoum e Tognini (1954), Grelle e Nahoum (1957), Rezende et al. (1959)

Departamento de Tocoginecologia da Universidade Federal de São Paulo - Escola Paulista de Medicina, São Paulo.

Correspondência:

Rosiane Mattar

Rua Desembargador do Vale, 81 apto 21-B

05010-040 - São Paulo - SP referiram 1 caso cada e Lippi et al. (1981), 2 casos. Entre os relatos mais recentes destacam-se Vianna Jr et al. (1985) e Menezes et al. (1986), ambos assinalando sucesso na intervenção. A maior casuística em nosso meio continua sendo de Camano $^{3}$ (1973) com 13 casos, com 6 crianças vivas ao nascimento e índice de sucesso de $46,2 \%$.

A chave do êxito desta intervenção está na ação imediata, e em vista da urgência do procedimento, a operação pode ser realizada sem o consentimento de familiares, segundo Fávero ${ }^{4}$ e Villalobos et al. ${ }^{5}$.

Cloud $^{6}$ e Villalobos et al. ${ }^{5}$ recomendaram que a cesariana deve ser praticada no próprio local da morte, não sendo necessário o consentimento de familiares para a realização do procedimento.

Sob nossa óptica e à luz dos preceitos morais e normas médico-legais julgamos que todo o feto tem o direito de ser um recém-nascido e que o obstetra deve ser responsável pela vida, não somente da mãe mas também do concepto. Devemos considerar que esta intervenção pode eventualmente salvar uma criança que tinha 100\% de possibilidade de morte.

Apesar de a cesariana pós-morte ser a mais antiga das tocurgias e do número de trabalhos que estudaram o assunto, julgamos haver alguns 
aspectos duvidosos e contraditórios que são percebidos no momento em que temos que indicála, e que, portanto, merecem maior discussão. Por esta razão resolvemos apresentar este estudo baseado nos casos ocorridos na UNIFESP- EPM durante os últimos anos.

\section{Pacientes e Métodos}

O estudo foi efetuado no período de janeiro de 1988 a dezembro de 1998, no Hospital São Paulo (HSP) da UNIFESP - Escola Paulista de Medicina. Durante esse período foram observadas 11 ocorrências de cesariana pós-morte em 12.345 partos .

Observamos na Tabela 1 o número de partos ocorridos em nosso serviço bem como a porcentagem de casos em que se praticou a cesariana pós-morte. Observa-se que no período a cirurgia foi efetuada numa taxa de 0,89/1.000 nascidos vivos num total de 11 casos em 83 mortes maternas.

Tabela 1 - Mortes maternas (MM) e cesariana pós-morte (CPM) no HSP relacionando com nascidos vivos (NV) e número de partos (NP).

\begin{tabular}{rrrrccc}
\hline ANO & MM & \multicolumn{1}{c}{ NP } & \multicolumn{1}{c}{ NV } & CPM & CPM/1.000NV & CPM/1.000NP \\
\hline 1988 & 9 & 1.316 & 1.273 & 2 & 1,5 & 1,6 \\
1989 & 8 & 1.054 & 1.015 & 1 & 0,9 & 0,9 \\
1990 & 14 & 1.315 & 1.334 & 0 & 0 & 0 \\
1991 & 6 & 1.067 & 1.038 & 1 & 0,9 & 0,9 \\
1992 & 12 & 869 & 587 & 2 & 2,3 & 3,4 \\
1993 & 9 & 1.131 & 1.084 & 1 & 0,9 & 0,9 \\
1994 & 4 & 1.149 & 1.099 & 0 & 0 & 0 \\
1995 & 11 & 757 & 729 & 3 & 4,0 & 4,1 \\
1996 & 4 & 1.180 & 1.116 & 0 & 0 & 0 \\
1997 & 5 & 1.283 & 1.253 & 1 & 0,8 & 0,8 \\
1998 & 1 & 1.224 & 1.210 & 0 & 0 & 0 \\
Total & 83 & 12.345 & 11.738 & 11 & 0,89 & 0,9 \\
\hline
\end{tabular}

Dos casos estudados, 4 (36\%) foram encaminhados de outros serviços médicos pelo fato de o HSP servir como hospital de referência terciária no Município de São Paulo, podendo fornecer melhor assistência em casos graves.

Analisamos as causas que determinaram o óbito materno e o intervalo de tempo entre a internação e a intervenção.

As gestantes foram caracterizadas pela idade, raça, estado civil e número de gestações. Foi estudada a idade gestacional em que se deu o evento e avaliamos dados relacionados ao parto e ao recém-nascido.

\section{Resultados}

Os nossos resultados encontram-se nas Tabelas 2 - 6 .

$\mathrm{Na}$ Tabela 2 verificamos que os 11 casos decorreram de diferentes doenças com 1 caso atribuído a cada uma.

Tabela 2 - Causas de morte materna nos casos submetidos a cesárea pós-morte, no período de 1988-1997.

\begin{tabular}{ll}
\hline Ano & Causa da morte \\
\hline 1988 & Encefalite viral necrotisante \\
1988 & AVCH \\
1989 & Abscesso perirrenal \\
1991 & Dissecção da aorta torácica \\
1992 & Trombose de seio cavernoso \\
1992 & Aneurisma cerebral roto \\
1993 & Miocardite aguda \\
1995 & Neurotoxoplasmose \\
1995 & Embolia amniocaseosa \\
1995 & Trauma crânio-encefálico \\
1997 & Pielonefrite aguda
\end{tabular}

1 caso em cada causa com porcentagem de 9,1\%

Na Tabela 3 mostramos que em $64 \%$ dos casos, o óbito ocorreu antes de completadas as 48 horas de internação.

\begin{tabular}{lcc}
\multicolumn{3}{l}{ Tabela 3 - Intervalo entre a internação e a intervenção } \\
\hline Intervalo & $\mathbf{n}$ & $\%$ \\
\hline$<48$ horas & 7 & 64 \\
$\geq 48$ horas & 4 & 36 \\
Total & 11 & 100 \\
\hline
\end{tabular}

$\mathrm{Na}$ avaliação dos casos de CPM quanto a raça e estado civil não houve predomínio entre os grupos pesquisados: $55 \%$ das pacientes eram brancas e 45\% não-brancas, encontrando-se essa mesma distribuição quando se compararam solteiras e casadas.

Ao estudarmos a idade gestacional de ocorrência da intervenção verificamos que em 3 casos a idade gestacional era inferior a 26 semanas e 8 casos estavam com 26 semanas ou mais de gestação.

A faixa etária predominante foi a de 20 a 30 anos, com $64 \%$ dos casos (Tabela 4), ao passo que as multigestas representaram $54 \%$ do total. 
Tabela 4 - Distribuição dos casos submetidos à cesárea pós-morte, segundo a faixa etária materna.

\begin{tabular}{lrr}
\hline Idade & $\mathbf{n}$ & $\%$ \\
\hline$<20$ anos & 2 & 18 \\
20 a 30 anos & 7 & 64 \\
$>30$ anos & 2 & 18 \\
Total & 11 & 100
\end{tabular}

Os fetos nascidos vivos foram sete, dos quais 2 entre as gestações com idade inferior a 26 semanas (Tabela 5).

Tabela 5 - 0 número de nativivos (sucesso da tocurgia) segunda a idade gestacional.

\begin{tabular}{|c|c|c|c|}
\hline Condições do parturido & $\mathrm{n}$ & $<26$ semanas & $\geq 26$ semanas \\
\hline Nativivo & 7 & 2 & 5 \\
\hline Natimorto & 4 & 1 & 3 \\
\hline Total & 11 & 3 & 8 \\
\hline
\end{tabular}

A incisão preferida foi a corporal (6 casos). A incisão transversa foi efetuada em 5 dos casos com idade gestacional superior a 26 semanas (Tabela 6).

Tabela 6 - Relação entre a incisão uterina e a idade gestacional.

\begin{tabular}{lcc}
\hline Incisão uterina & $<26$ semanas & $\geq 26$ semanas \\
\hline Corporal & 3 & 3 \\
Transversa & 0 & 5 \\
Total & 3 & 8 \\
\hline
\end{tabular}

\section{Discussão}

Em 13,2\% dos casos de morte materna ocorridos no HSP, indicou-se cesariana pós-morte. Apesar de o evento ser raro, representou mais de $10 \%$ das mortes maternas ocorridas em nosso serviço. Quando comparado com o número de partos ou o número de nascidos vivos, o acontecimento teve incidência baixa, correspondente a 0,9/1.000 partos e 0,89/1.000 nascidos vivos.

Entre as causas que levaram as gestantes ao óbito observamos que as patologias neurológicas foram as mais freqüentes, distribuindo-se preferencialmente em ocorrências de origem vascular, como o acidente vascular cerebral, trombose de seio venoso e aneurisma cerebral roto, além da encefalite viral necrotisante e a neurotoxoplasmose como causas infecciosas.

À semelhança do que ocorre no primeiro mundo, onde os acidentes automobilísticos constituem importante causa de óbito em pacientes jovens, o trauma crânio-encefálico também fez parte de nossa casuística. Referências clássicas como a embolia amniocaseosa, bem como causas cardiológicas como a dissecção da aorta torácica e a miocardite aguda, também foram encontradas.

Observamos dois óbitos maternos por abscesso perirrenal e outro por pielonefrite, que constituem causas facilmente evitáveis com assistência pré-natal adequada e instituição de terapêutica eficaz.

Apuramos que em 7 casos a patologia acometeu a gestante de forma repentina e apenas 1 dos 11 casos apresentados se deveu a doença crônica (neurotoxoplasmose em paciente portadora de doença pelo vírus da imunodeficiência adquirida).

Pudemos observar que $64 \%$ das tocurgias foram realizadas antes que se completassem 48 horas entre a internação e a intervenção, periodo necessário para se confirmar a hipótese diagnóstica presumida, mostrando a evolução rápida da patologia que determinou a morte materna.

Em $91 \%$ dos casos, portanto, a causa da morte acometeu as gestantes de forma aguda, o que caracteriza a população em que habitualmente se indica a cesariana pós-morte. Camano ${ }^{3}$ assinalou com propriedade que os óbitos maternos precedidos de agonia prolongada ou enfermidade crônica deterioram o estado do concepto por hipóxia progressiva, com pior prognóstico fetal.

Acredita-se, também, que a chave do êxito desta intervenção está na ação imediata após a morte materna, visando evitar o comprometimento do bem-estar fetal. Há consenso na literatura pertinente que, quanto mais próximo da morte for realizado o procedimento, melhor é o prognóstico fetal. Assim, não se justifica o apuro na identificação dos batimentos cardiacos fetais.

Weber $^{7}$ graduou o sucesso da cirurgia na dependência do tempo despendido para o início da cirurgia em minutos: menor de 5 minutos, excelente; 5 a 10 minutos, bom; 10 a 15 minutos, duvidoso; 15 a 25 minutos, há pouca possibilidade de sucesso.

Vários autores indicaram o procedimento até o $25^{\circ}$ minuto da morte da paciente, entre os quais, destacam-se os brasileiros Grelle e Nahoum ${ }^{8}$. Outros autores, como Breen e Peraglie ${ }^{9}$ e Lopez ${ }^{10}$, estendem a indicação até o $30^{\circ}$ minuto, por terem obtido criança viva após esse tempo de decesso materno.

Gostaríamos de ressaltar que essas informações, como o intervalo de tempo entre o diagnóstico de morte e o início da intervenção, que tem intima relação com o prognóstico fetal, não puderam ser analisadas, pois não constavam dos prontuários. 
Quando analisamos as idades das gestantes, observamos que a grande maioria encontrava-se entre 20 a 30 anos, correspondendo a $64 \%$ dos casos ocorridos. Lamenta-se, portanto, que os casos de mortalidade materna e cesariana pós-morte ocorram predominantemente em pacientes mais jovens e de maior produtividade, achado coincidente com a literatura ${ }^{7,11}$.

Verificou-se que o evento é mais freqüente em multigestas. Quando comparamos com os dados da literatura observamos que Lope ${ }^{10}$ obteve $61,5 \%$ de casos em multigestas, ao passo que Weber ${ }^{7}$ apresentou $50,0 \%$ e Camano et al. ${ }^{11}$ referiram $36,36 \%$.

Entre nossos casos de cesariana pós-morte houve $64 \%$ de nativivos. A literatura médica assinala vários sucessos dessa intervenção. Behney ${ }^{12}$ relatou 150 casos de sucesso até o ano de 1961 e destes, 11 crianças tiveram desenvolvimento normal após 3 a 8 anos de seguimento.

Acreditamos que nossos bons resultados se devam ao fato de que 5 nativivos $173 \%$ das gestantes) tinham idade gestacional superior a 26 semanas. Porém, abaixo dessa idade gestacional, onde a indicação é duvidosa, tivemos 3 ocorrências e dois casos de nativivos. Esse número nos leva a refletir sobre a validade da cesariana pós-morte em idades gestacionais precoces, visto que a indicação clássica da literatura, citada por diversos autores como Cloud ${ }^{6}$, Villalobos et al. ${ }^{5}$, Breen e Peraglie $^{9}$ e Arthur ${ }^{13}$, recomenda o procedimento somente em idades gestacionais superiores a 28 semanas.

O sucesso da intervenção, em relação aos resultados perinatais, guarda relação com a assistência neonatal disponivel no momento emergencial.

Observamos que em idades gestacionais superiores a 26 semanas houve distribuição praticamente semelhante entre a escolha da incisão uterina corporal e transversa, talvez porque quando o segmento uterino está formado, o obstetra sentese seguro em indicar o talho uterino sobre o segmento, mesmo em situações de emergência em que a opção corporal seria a mais prática. Este resultado não obedece às indicações encontradas na literatura, onde Smith ${ }^{14}$, Weber ${ }^{7}$ e Dumont ${ }^{15}$ recomendaram a incisão uterina corporal, que é de execução fácil e rápida, de acordo também com nossa orientação. Rezende ${ }^{1}$ e Camano ${ }^{3}$ lembraram que a seqüência operatória deve ser obediente aos preceitos cirúrgicos. Strong e Lowe ${ }^{16}$ recomendaram que nas salas de emergência dos hospitais haja uma caixa cirúrgica para a realização do procedimento.

O prognóstico do recém-nascido na cesariana pós-morte guarda relação íntima com o pronto e correto atendimento à gestante terminal e depende de uma série de variáveis, entre elas o intervalo de tempo entre a morte materna e o início do procedimento e a assistência adequada ao recémnascido, muitas vezes prematuro, mas que em condições adequadas pode sobreviver sem seqüelas.

Alguns aspectos continuam polêmicos, como a idade gestacional mínima em que o procedimento deve ser realizado, o tempo limite máximo para início da intervenção, se esta prática deve ficar restrita ao profissional médico ou pode ser estendido a outros profissionais de saúde, como enfermeiras obstétricas ou paramédicos, e a participação da família na anuência do procedimento.

Assim, mesmo a cesariana pós-morte sendo a mais antiga das cirurgias obstétricas, tendo relatos que datam de milênios, alguns aspectos precisam continuar a ser analisados e discutidos de modo que a alteração de algumas variáveis importantes possam levar ao êxito da intervenção.

Em nossa visão, diante do atendimento a gestantes em estado terminal, todo o esforço deve ser realizado tendo como objetivo principal prestar o melhor atendimento ao nascituro.

\section{SUMMARY}

Objectives: to analyze the medical and legal aspects in order to contribute to the study and standardization of this obstetrical surgery in Brazil.

Methods: our study was based on 11 cases of cesarean section performed in the imminence of maternal death or just after death. These cases were attended at UNIFESP - EPM from 1988 to 1998.

Results: there were 7 live births, five of them with a gestational age over 26 weeks. Most deaths occurred within the first 48 hours after admission. The predominant age range was the third decade.

Conclusions: although postmortem cesarean section is indicated to save the fetus, it is rarely performed. The conditions for its indication involve knowledge of the technique as well as of the ethical and legal principles.

KEY WORDS: Postmortem cesarian section. Cesarean section. Maternal mortality.

\section{Referências}

1. Rezende J. Operação cesariana. In: Rezende J, editor. Obstetrícia. 4 ed. Rio de Janeiro: Guanabara Koogan; 1982.p.963-1016. 
2. Bertini-Oliveira AM, Camano L. Morte súbita em obstetrícia. Femina 1985; 13: 981-3.

3. Camano L. Cesárea pós-morte: análise estatística de treze casos ocorridos na Casa Maternal e da Infância da L.B.A.. Mat. Inf. 1973; 32: 337-46.

4. Fávero R. Cesarea post-mortem. Mat Inf 1951; 10: 207-18.

5. Villalobos MR, Karchmer SK., Gonzalez GZ. Operacion cesarea postmortem y en la paciente agonica. Ginecol Obstet Mex1967; 22: 607-17.

6. Cloud IG. Cesarean section on the dead and the moribund. Obstet Gynecol 1960; 16: 27-30.

7. Weber CE. Postmortem cesarean section: review of the literature and case reports. Am J Obstet Gynecol 1971;110: 158-65.

8. Grelle FC, Nahoum JC. A cesárea post mortem: condições para sua realização: problemas éticos e médico-legais. Rev Bras Med 1957;14:470-5.
9. Breen JL, Peraglie BR. Postmortem cesarean section; report of a case. Pac Med Surg 1966; 74:102-4.

10.Lopez DM. Cesarea post-mortem. Rev Obstet Ginecol Venezuela 1968; 28: 129-46.

11.Camano L, Junqueira MLM, Bertini-Oliveira AM. Cesárea post mortem. Femina 1985; 13: 550-8.

12.Behney CA. Cesarean section delivery after death of the mother. JAMA 1961;176: 617-9.

13.Arthur RK. Postmortem cesarean section. Am J Obstet Gynecol 1978;132:175-9.

14.Smith GE. Postmortem caesarean section; a case report. J Obstet Gynaecol Br Commonn 1973; 80: 181-2.

15.Dumont M . La césarienne post-mortem. Nouv Presse Med 1981; 10: 251-2.

16.Strong TH Jr, Lowe RA. Perimortem cesarean section. Am J Emerg Med 1989; 7:489-94 